CDD: 110

\title{
Determinism, Laws of Nature and the Consequence Argument
}

\section{Pedro Merlussi}

Durbam University

Department of Philosophy

CAPES Foundation, Ministry of Education of Brazil, Brasilia - DF 70040-020, Brazil.

50 Old Elvet

Durham DH1 3HN

pedro.merlussi@durham.ac.uk

Received: 16.10.2014; Revised: 21.09.2015; Accepted: 29.03.2016

DOI: http://dx.doi.org/10.1590/0100-6045.2016.V39N1.PM

\begin{abstract}
Scott Sehon (2011) argues that the conception of determinism employed in the Consequence Argument is implausible because it rules out the logical possibility of the laws of nature being violated. Sehon says, for instance, that determinism is incompatible with the logical possibility of an interventionist God (IG). His objection to the Consequence Argument boils down to a way of reading the box in what is implied by van Inwagen's conception of determinism. Sehon reads the box as logical necessity, and this clearly precludes the logical possibility of the laws of nature being violated. However, I argue that determinism as employed in the argument is not implausible. First, I try to show that it is legitimate to read the box of $\square\left(\left(\mathrm{P}_{0} \& L\right) \supset P\right)$ as either metaphysical or logical necessity depending on the account of laws that one assumes. If one accepts a fully Humean account of laws, then the box should be read as logical necessity. Nevertheless, I argue that this is not a problem for the Humean. On the other hand, if one reads the box as metaphysical necessity, which is mainly motivated by the dispositional account of laws and might be motivated by Armstrong's account, then determinism is compatible with the logical possibility of the laws being violated.
\end{abstract}

Keywords: determinism; laws of nature; the Ramsey-Lewis account of laws; Armstrong's account of laws; dispositional essentialism; metaphysical necessity. 


\section{The Modal Consequence Argument}

Incompatibilism is the thesis according to which if determinism is true, it is also true that there is no free will. The main argument in the contemporary debate for incompatibilism is the Consequence Argument. If the Consequence Argument is cogent, then determinism is incompatible with free will. In this paper I will start with the modal version of the argument presented by van Inwagen (1983), since Sehon's objection is directed to it.

Intuitively, determinism is just the thesis according to which the past and the laws of nature determine a unique future. Let ' $\mathrm{P}_{0}$ ' be an abbreviation for a sentence expressing a true proposition about the total state of the world at some time in the distant past, ' $L$ ' an abbreviation for a sentence expressing a conjunction of all the laws of nature and 'P' may be substituted by any sentence that expresses a true proposition. If determinism is true, then $\square\left(\left(\mathrm{P}_{0} \& \mathrm{~L}\right) \supset \mathrm{P}\right)$.

Furthermore, the argument uses the modal sentential operator ' $N$ ', where ' $\mathbf{N} P$ ' abbreviates ' $P$ and no one has, or ever had, any choice about whether $P$ '. There is no complete and plausible logic for the ' $\mathbf{N}$ ' operator, but for now we will assume that following rules are valid:

(a) $\square \mathrm{P} \vdash \mathrm{NP}$

$(\beta) \mathbf{N}(\mathrm{P} \supset \mathrm{Q}), \mathrm{NP} \vdash \mathrm{NQ}$

Now I am able to put forward the modal version of the Consequence Argument:

1. $\square\left(\left(\mathrm{P}_{0} \& L\right) \supset P\right)$

follows from determinism

2. $\square\left(\mathrm{P}_{0} \supset(L \supset P)\right)$

from 1

3. $\mathbf{N}\left(\mathrm{P}_{0} \supset(L \supset P)\right)$

from 2 and rule $(\alpha)$

4. $\mathrm{NP}_{0}$

premise

5. $\mathbf{N}(L \supset P)$

from 3, 4 and rule $(\beta)$

6. $\mathbf{N} L$

premise

Manuscrito - Rev. Int. Fil., Campinas, v.39, n.1, pp. 73-95, jan.-mar. 2016. 
7. $\mathbf{N} P$

from 5,6 , and rule $(\beta)$

Sehon's objection to the argument above boils down to a way of reading the box in ' $\square\left(\left(\mathrm{P}_{0} \& \mathrm{~L}\right) \supset \mathrm{P}\right)$ ', which is supposed to be implied by determinism. Sehon reads the box as logical necessity, as he says (2011:31):

According to premiss (1) as it stands, the truth of determinism would mean that the laws of nature plus the facts as they stood at some point in the distant past logically necessitate any true sentence, e.g. that I had coffee with breakfast this morning or that there is water in the glass on my right. This seems problematic.

The reason why Sehon thinks this is problematic is because it precludes the logical possibility of the laws of nature being violated. He presents his argument saying that determinism is incompatible, in particular, with the logical possibility of an interventionist God (IG). In other words, determinism in the Consequence Argument implies that an IG is logically impossible. Assuming that an IG is not a logical impossibility, it certainly looks like a serious blow to the Consequence Argument.

According to Sehon's conception of an IG, 'God has the ability to intervene in the natural order, and, for example, miraculously change water into wine' (2011:31). This means that the logical possibility of the existence of an IG strictly implies that $\square\left(\left(\mathrm{P}_{0} \& \mathrm{~L}\right) \supset \mathrm{P}\right)$ is false. In other words, as Sehon says, 'necessarily, if an IG exists, then it is possible that the same initial state of affairs obtains, along with the same laws of nature, and yet $\mathrm{P}$ is false - i.e it is possible that $\mathrm{P}_{0} \& \mathrm{~L} \& \sim \mathrm{P}$ ' (2011:31)'. His reasoning is spelled out as follows:

1. $\square\left(\mathrm{IG} \supset \diamond\left(\mathrm{P}_{0} \& \mathrm{~L} \& \sim \mathrm{P}\right)\right) \quad$ Premise

2. $\diamond \mathrm{IG}$

Premise

3. $\diamond\left(\mathrm{P}_{0} \& \mathrm{~L} \& \sim \mathrm{P}\right)$

From $1 \& 2$, assuming $\mathrm{S} 4$

4. $\sim \square\left(\left(\mathrm{P}_{0} \& \mathrm{~L}\right) \supset \mathrm{P}\right)$

From 3 
If there is no problem with premises 1 and 2, as well as the inference based on S4 or any stronger system, it seems that we can simply deny, as Sehon does, the first premise of the Consequence Argument. Contrary to what proponents of the Consequence Argument say, determinism does not imply $\square\left(\left(\mathrm{P}_{0} \& \mathrm{~L}\right) \supset \mathrm{P}\right)$.

Note that Sehon's main point does not depend on the premise that an IG is logically possible. For instance, someone could argue as follows. What if we say that determinism implies the doctrine that ' $\mathrm{P}_{0} \& \mathrm{~L} \& \sim \mathrm{G}$ ' strictly implies $P$, where $\sim G$ is the proposition that God does not intervene in the natural order? This is consistent with accepting that 'IG' is logically possible, and hence is consistent with IG.

The problem above is that determinism would be incompatible, say, with the logical possibility of an interventionist demon, in the sense that, necessarily, if an interventionist demon exists, then it is possible that $\mathrm{P}_{0} \& \mathrm{~L} \& \sim \mathrm{G} \& \sim \mathrm{P}$. Therefore, the conception of determinism employed in the Consequence Argument is implausible.

Sehon's main worry is not about the logical possibility of an IG, or about the logical possibility of a demon in particular. It is about the logical possibility of the laws of nature being violated or broken. Determinism is supposed to be an empirical claim, and as such should not rule out the logical possibility of the laws of nature being broken. Sehon seems to think it is obvious that an empirical claim should not preclude this logical possibility. One could contend that this is not obvious at all. But suppose Sehon is right. Suppose that an empirical claim could not preclude such a logical possibility. This would be a serious problem to the conception of determinism employed in the Consequence Argument.

\section{Determinism and metaphysical necessity}

First of all, it should be noted that, in the previous reasoning, Sehon reads boxes and diamonds as logical necessity and possibility. Thus, this reasoning is only relevant if the box of $\square\left(\left(\mathrm{P}_{0} \& \mathrm{~L}\right) \supset \mathrm{P}\right)$ is read as logical necessity. It will be clearer if I present his reasoning again. Let ' $\square$ ' ' stand for logical necessity. 


\section{1. $\square_{1}\left(\mathrm{IG} \supset{ }_{1}\left(\mathrm{P}_{0} \& \mathrm{~L} \& \sim \mathrm{P}\right)\right) \quad$ Premise}

2. $\diamond_{1} \mathrm{IG}$

3. $\diamond_{1}\left(\mathrm{P}_{0} \& \mathrm{~L} \& \sim \mathrm{P}\right)$

4. $\sim \square_{1}\left(\mathrm{P}_{0} \& \mathrm{~L} \supset \mathrm{P}\right)$
Premise

From $1 \& 2$, assuming $\mathrm{S} 4$

From 3

As we can see, 4 implies the contradictory of $\square\left(\left(\mathrm{P}_{0} \& \mathrm{~L}\right) \supset \mathrm{P}\right)$ if the box of is read as logical necessity.

My reply is very straightforward. What follows from determinism here does not need to be read as logical necessity. It might rather be read as metaphysical necessity. Let ' $\square_{\mathrm{m}}$ ' stand for metaphysical necessity. This is how one might understand what follows from determinism:

$$
\text { (M) } \square_{\mathrm{m}}\left(\left(\mathrm{P}_{0} \& \mathrm{~L}\right) \supset \mathrm{P}\right)
$$

Now it is clear that

$$
\text { (L) } \sim \square_{1}\left(\left(\mathrm{P}_{0} \& \mathrm{~L}\right) \supset \mathrm{P}\right)
$$

and

$$
\text { (M) } \square \mathrm{m}\left(\left(\mathrm{P}_{0} \& \mathrm{~L}\right) \supset \mathrm{P}\right)
$$

are not explicitly contradictory. So, in this case, the logical possibility of an IG (or a demon, or the laws of nature being violated) is compatible with the conception of determinism employed in the Consequence Argument. This is so because we are dealing with two different sorts of modality. For instance, consider the following set:

$$
\text { (S) }\left\{\sim \square_{1}\left(\left(\mathrm{P}_{0} \& \mathrm{~L}\right) \supset \mathrm{P}\right), \square_{\mathrm{m}}\left(\left(\mathrm{P}_{0} \& \mathrm{~L}\right) \supset \mathrm{P}\right)\right\}
$$


Set $(\mathrm{S})$ is not explicitly inconsistent, for $(\mathrm{L})$ and $(\mathrm{M})$ are not explicitly contradictory. For example, suppose that we define 'epistemic necessity' as follows:

$\Phi$ is epistemically necessary for a subject $S$ if and only if $\neg \Phi$ is ruled out by what $S$ knows.

Example: Given everything Jamie knows, it is necessary that the Brazilian economy will hit a recession in the coming months.

Let $\mathrm{P}$ stand for the proposition that the Brazilian economy will hit a recession in the coming months. Clearly, $\mathrm{P}$ is not logically necessary, since it is neither an axiom of any system, nor it is derivable from a system through its rules. Let ' $\square$ ' ' stand for epistemic necessity.

$$
\left(\mathrm{S}^{*}\right)\left\{\square_{\mathrm{e}} \mathrm{P}, \sim \square_{1} \mathrm{P}\right\}
$$

Set $\left(S^{*}\right)$ is not explicitly inconsistent, for $\square_{\mathrm{e}} \mathrm{P}, \sim \square_{1} \mathrm{P}$ are not contradictory. In our present case, set (S) is not explicitly inconsistent either. At a first glance, (L) and (M) are not contradictory.

Someone may reply that set (S), despite not being explicitly inconsistent, may be implicitly inconsistent. All we need to do is to find a true necessary proposition that allows one to deduce a contradiction from it. The proposition that can do this job is the one expressed by the sentence 'logical possibility entails metaphysical possibility'. Well, $(\mathrm{L})$ is simply the thesis that $\widehat{ }_{1}\left(\mathrm{P}_{0} \& \mathrm{~L} \& \sim \mathrm{P}\right)$. If logical possibility entails metaphysical possibility, then one gets the contradictory of $(\mathrm{M})$; and then set $(\mathrm{S})$ is implicitly contradictory.

Surely, if logical possibility entails metaphysical possibility, then (M) is incompatible with the logical possibility of the laws of nature being violated. But does logical possibility entail metaphysical possibility? We cannot assume it as self-evident. Some philosophers think that there are logical possibilities that are not metaphysical possibilities. We customarily call these philosophers 'essentialist philosophers'. As Shalkowski writes, essentialist claims 'usually involve logical possibilities that are not metaphysical possibilities' (Shalkowski 2004: 61). One may say that the conditional is intuitively false. It is logically possible that Socrates is a VISA credit card, but this is not metaphysically possible.

If there are some logical possibilities that are not metaphysical possibilities, and if one reads the box of $\square\left(\left(\mathrm{P}_{0} \& \mathrm{~L}\right) \supset \mathrm{P}\right)$ as metaphysical necessity, 
then determinism as employed in the Consequence Argument is compatible with an IG being logically possible. However, everything I said so far is that one might read the box as metaphysical necessity. And this seems too weak. After all, why on earth should one read the box as metaphysical necessity? I try to show that it is legitimate to read the box as either metaphysical or logical necessity depending on the account of laws that one assumes. If one accepts a fully Humean account of laws, then the box should be read as logical necessity, just like Sehon does. But this does not need to be the case for other accounts that are not fully Humean.

So, I will show that there is motivation for accepting the conception of determinism that I suggested in this paper. And the motivation, I argue, springs from certain accounts of laws. What I am going to do in the next section is the following. I will initially consider two accounts of lawhood. First, I will briefly characterize Lewis's and Armstrong's accounts. Then, following Helen Beebee (2000), I highlight the implications of these two accounts for determinism. I indicate that Armtrong's view might be in line with my understanding of what is implied by determinism, while what is implied by Lewis's account is just the view that Sehon criticizes. In any case, I shall argue that Sehon's criticism is not a problem for those who accept a Lewisian account of laws.

Ultimately, I consider the dispositional account, trying to explore the consequences of dispositional essentialism for determinism. According to this view, at least some properties are essentially dispositional, and the laws of nature are derived from a claim about the essence of these dispositions plus the conditional analysis of dispositions. Given the dispositional account of laws, I show that there is a natural way for reading the box as metaphysical necessity.

\section{Determinism and two accounts of lawhood}

If we were to characterize determinism in a preliminary way, we would have something like this: determinism is the doctrine that the past and the laws of nature determine a unique future. What we might naturally wonder is what 'determine' means here. Since Sehon reads the box as logical necessity, he takes proponents of the Consequence Argument to assume that the past and the laws determine a unique future in a logical fashion. That is, if determinism is true, one can deduce propositions about the future from $\mathrm{P}_{0}$ and $\mathrm{L}$. This is certainly a natural 
way to understand the doctrine of determinism. Nevertheless, following Beebee (2000), I show that this is a way of understanding the meaning of 'determine' that is based on a fully Humean approach of laws. And proponents of the Consequence Argument do not need to be (and, in fact, should not be) committed to a fully Humean view about laws. Let us take a look at this in a bit more detail.

First, following Alexander Bird (2007), I will describe a view as Humean if it states that it is not the case that there are necessary connections in nature. We have then three views of laws that Bird characterizes as fully Humean, semiHumean and anti-Humean (Bird 2007: 2). On the fully-Humean side, we have the so-called Ramsey-Lewis view according to which laws merely summarize events. On the semi-Humean side, there is the Armstrong view which says that a law of nature is a relation of necessitation between universals. His view is characterized as semi-Humean because Armstrong is not committed to the idea that laws are metaphysically necessary. On the anti-Humean side I will consider Bird's view. Now, when I say that proponents of the Consequence Argument do not need to be committed to a fully Humean view about laws I naturally want to refer to the Ramsey-Lewis account. Things are not so clear with respect to Armstrong's view, but I will at least indicate that his view may be in line with my understanding of determinism.

Let me start then with the Ramsey-Lewis view, which says that a regularity is a law of nature if and only if it appears as an axiom in each of a true deductive systems that achieves a best combination of simplicity and strength (Lewis 1973: 73). We can think of a true deductive system as a set of true sentences $T$ that is deductively closed. To say that $T$ is deductively closed is to say that every sentence that can be deduced from $\mathrm{T}$ is itself a member of $\mathrm{T}$. The sentences that are logical consequences of $\mathrm{T}$ are its theorems. And there are many ways in which systems can be axiomatized. Some systems are stronger than others, in the sense that they have more information content. Some true deductive systems can be axiomatized simpler than others, in the sense that they have fewer axioms. We can have, for example, a very strong system that is the conjunction of all true sentences. But the complexity of such a system would not make it useful. On the other hand, we can have a less complex and simple system, only with some mathematical and logical truths. But this system would not allow us to deduce important regularities about the world. The laws of nature will 
belong to all the systems with a best combination of these two virtues, simplicity and strength.

On this view, laws supervene on the particular matters of fact (facts about what objects exist, the relations they stand in to one another as well as the properties they instantiate). This is so because this view tries to maintain the Humean intuition that laws merely summarize facts. Laws do not 'govern' the world, they are just descriptive. The particular matters of fact determine ${ }^{1}$ the laws of nature in the sense that if we have the same particular matters of fact, we have the same laws. This sharply contrasts with Armstrong's view because, for Armstrong, supervenience does not hold for laws, so that it is possible to have the same particular matters of facts with different laws of nature. I will not discuss, nonetheless, the alleged counterexamples against the supervenience thesis (see further Carroll 1994 and Beebee 2000).

A law of nature for Armstrong, on the other hand, is not a regularity, but a relation of necessitation between universals. Suppose it is a law that F's are G's. F-ness and G-ness are taken to be first order universals. Armstrong states that a second order relation holds between these two universals. He labels this relation as 'nomic necessitation' and he uses ' $N$ ' to refer to it. Armstrong symbolizes the relation of necessitation between $F$ and $G$ as ' $N(\mathrm{~F}, \mathrm{G})$ '. He then tells us that the holding of $N$ entails the corresponding generalization. If the second order relation $N$ holds between the first order universals $F$ and $G$, then ' $N(\mathrm{~F}, \mathrm{G})$ ' entails 'All F's are G's'. Keep in mind that the necessitation relation is a contingent one: according to Armstrong, for example, there actually is a necessary connection between, say, force, mass and acceleration. But this relation might not exist. If we allow ourselves to use the idiom of possible worlds, in the actual world two first order universals may be related by $N$, whereas in another possible world they might not be.

Although they agree that laws are contingent, the differences between these accounts are clear. First, as I already said, for Lewis the laws of nature supervene on the particular matters of fact, contrary to Armstrong's view. Second, their conception of determinism differs in a way that stems from their accounts of laws. I will point out the differences about their understanding of

${ }^{1} \mathrm{I}$ am using the term 'determination' here in the sense that A determines B iff sameness with respect to A implies sameness with respect to B. 
determinism based on Beebee's (Beebee 2000: 578) considerations. What is determinism then according to these accounts?

For the fully Humean, if determinism is true, then $\mathrm{P}_{0}$ and L strictly imply P2 (see for example Lewis, 1983: 360). As Beebee says:

For the [fully] Humean, the laws and the current facts determine the future facts in a purely logical way: you can deduce future facts from current facts plus the laws. And this is just because laws are, in part, facts about the future' (Beebee 2000: 578).

For the fully Humean view, we do not have laws if we rule out future facts, for we need all the facts, including future ones, in order to have those statements that will summarize them all. As Frank Ramsey once wrote, even 'if we knew everything, we would still want to systematize our knowledge as deductive system, and the general axioms in that system would be the fundamental laws of nature' (1978: 31). The intuition here is just the following. Following Beebee again, suppose we have a list about all the particular matters of fact and suppose we want to learn everything about this list ${ }^{3}$. The list would naturally be a tedious one, and it would include all the true sentences describing everything that happened and will happen. But if there are laws of nature, for the Ramsey-Lewis account, we have those axioms that figure in a system which is a best combination of strength and simplicity. Not surprisingly, these axioms will also include future facts, since the intuition that the Humean wants to capture is that laws compile all past, present and future facts. Thus, when the Humean says that the laws and the past determine a unique future, she just has in mind that one can deduce sentences about the future from $\mathrm{P}_{0}$ and $\mathrm{L}$ if determinism is true.

Notwithstanding, things are different for Armstrong. While for the fully Humean laws are in part dependent on future facts, for Armstrong it is just the

${ }^{2}$ The way Lewis defines it is given as follows: 'a system of laws of nature is deterministic iff no two divergent worlds both conform perfectly to the laws of that system' (Lewis, 1983: 360). Possible worlds diverge if, despite having duplicate initial temporal segments, they are not duplicates. So, the idea is that two distinct deterministic worlds cannot have the same laws if they have the same past.

${ }^{3}$ Note, however, that the Ramsey-Lewis account is not an epistemic view. I am just putting in this way for the sake of simplicity, just like Beebee (2000) does.

Manuscrito - Rev. Int. Fil., Campinas, v.39, n.1, pp. 73-95, jan.-mar. 2016. 
other way round. As Beebee points out, 'the laws 'make' the future facts be the way they will be: the laws are the ontological ground of the future facts' (Beebee 2000: 578). Thus, Armstrong has a much more substantial conception of what determinism is than Lewis. Thus, the disagreement between him and Lewis is also a disagreement about whether what determinism implies should be understood in a purely logical way. The difference is that, for Armstrong, the laws 'make' the future events, rather than being also part of them, as for Lewis:

Imagine Armstrong writing down everything that's true of the universe up to this moment. One of the things that will appear in his list will be the obtaining of $N$ between various pairs of universals. And it's in the nature of $N$ that its obtaining entails that those universals will carry on occurring together. " $N(F, G)$ " expresses a relation that is already with us, so the future really is determined by some current feature of the universe. For the Humean, on the other hand, a complete list of everything that's true of the universe up to now entails nothing whatever about the future, since if future facts by definition are banned from the list, then so are laws of nature (Beebee 2000: 578-9).

The Ramsey-Lewis conception of determinism is totally in line with Sehon's understanding of this notion as formulated in the Consequence Argument. It is not totally clear, however, whether this is also the case for Armstrong. Actually I would say it is not. Remember that, as Beebee said, Armstrong takes the laws of nature to be the ontological ground of future facts. If the literature on ground has any bite, to say that A grounds B does not seem to be equivalent to saying that A entails B. For example, we may say that the proposition expressed by 'snow is white' entails the proposition expressed by 'either p or not-p' such that it is logically necessary that if snow is white, then either $\mathrm{p}$ or not-p. But this is merely because it is logically necessary that either $\mathrm{p}$ or not-p. We would not say that the fact that either $\mathrm{p}$ or not-p is grounded on the fact that snow is white. When we say that a certain fact grounds another there seems to be something more than entailment, that is, the facts seem to be connected through something else, namely ground. Hence, I think the Armstrongian conception of determinism does not need to be seen as equivalent to the fully Humean one.

How should one understand the statement that the laws of nature ground future facts? One suggestion might be the following (see Fine 2012: 39, although 
Fine himself is not committed to it): the fact that A grounds the fact that B iff the fact that $B$ obtains in virtue of the fact that $A$ and it is a metaphysical necessity that if A then B. Thus, we might understand what determinism implies in an Armstrongian fashion as the doctrine that future facts obtain in virtue of the past and the laws of nature and it is metaphysically necessary that $\mathrm{P}_{0}$ and $\mathrm{L}$ imply $\mathrm{P}$ (where $\mathrm{P}$ is any true proposition about the future). This is just what I think we should undertake in order to avoid Sehon's objection to the Consequence Argument.

It might be objected that I am befuddling nomic necessitation with metaphysical necessity. Using the idiom of possible worlds again, Armstrong's necessitation has nothing to do with 'true in all possible worlds'. Nomic necessitation is rather a second order relation between universals that is instantiated as causation, as Armstrong tells us (1997: 232). Against this objection I would say that I am not taking nomic necessitation as equivalent to metaphysical necessity. This is clearly not the case. The obtaining of $N$ is something that happens here and now, and prima facie has nothing to do with what happens in other possible worlds. What I am saying is just that, if laws ground future facts, this might (epistemic 'might') be understood just as I indicated above. Thus, there is a way in which we might understand Armstrong's view about laws that is in consonance with my formulation of determinism.

To sum up, it seems that if the Ramsey-Lewis view is correct, then we should read the box of $\square\left(\left(\mathrm{P}_{0} \& \mathrm{~L}\right) \supset \mathrm{P}\right)$ as logical necessity. If the Armstrong view is correct, then we might (again, epistemic 'might') read the box of $\square\left(\left(\mathrm{P}_{0} \& \mathrm{~L}\right) \supset \mathrm{P}\right)$ as metaphysical necessity. But the problem, someone may say, still remains. Even if we are going to read the box as metaphysical necessity, how are we to understand metaphysical necessity? If metaphysical necessity is just logical necessity, then even if what I suggested above is appropriate, determinism is still incompatible with an IG being logically possible. So it may be that the Armstrongian conception of determinism is incompatible with an IG being logically possible. This is fair enough. But if it is really the case, it is hard to see what is the difference between Armstrong's and Lewis's conceptions of determinism. After all, if metaphysical necessity is just logical necessity, Armstrong's understanding of $\square\left(\left(\mathrm{P}_{0} \& \mathrm{~L}\right) \supset \mathrm{P}\right)$ would just be something like 'the fact that $\mathrm{P}$ obtains in virtue of $\mathrm{P}_{0}$ and $\mathrm{L}$ and it is a logical necessity that if $\mathrm{P}_{0}$ and $\mathrm{L}$ then $\mathrm{P}$ '. The only difference then would be the in-virtue claim. But, as Fine says, 'we may call an in-virtue claim a statement of ontological or metaphysical ground

Manuscrito - Rev. Int. Fil., Campinas, v.39, n.1, pp. 73-95, jan.-mar. 2016. 
when the conditional holds of metaphysical necessity' (Fine 2012: 38). If we insist that metaphysical and logical necessities are equivalent, I do not see how their conceptions of determinism may be different. And there is a good motivation for thinking that they are different.

In any case, I am not going any further on this since my main interest here is in Bird's dispositional account, one that clearly disentangles metaphysical necessity from logical necessity. All I wanted to show is that it is not so implausible to read the box as metaphysical necessity if one is keen on assuming Armstrong's account of laws. If someone that agrees with Armstrong about the nature of laws is also willing to separate metaphysical necessity from logical necessity, then all the best.

Armstrong's conception of determinism at least might be compatible with the logical possibility of an IG. How about the fully Humean conception of determinism? If we accept the Ramsey-Lewis view of laws, then determinism is clearly incompatible with the logical possibility of an IG as characterized by Sehon. Does it mean that this view has as a very implausible result? I do not think so. In the next section I come with a brief remark about this question.

\section{Interlude: Is it logically possible to violate the laws?} follows:

If Sehon is right, one could argue against the Ramsey-Lewis view as

P1. If the Ramsey-Lewis account of laws is correct, then determinism is incompatible with an IG being logically possible.

P2. Determinism is not incompatible with an IG being logically possible. Therefore,

C. The Ramsey-Lewis account of laws is not correct.

The defence of P1 is this. $\diamond_{\mathrm{L}} \mathrm{IG}$ entails, according to Sehon, $\diamond_{\mathrm{L}}\left(\mathrm{P}_{0} \& \mathrm{~L}\right.$ $\& \sim \mathrm{P})$. But since the Ramsey-Lewis view formulates determinism as implying $\square$ $\mathrm{L}\left(\left(\mathrm{P}_{0} \& \mathrm{~L}\right) \supset \mathrm{P}\right)$, it follows that determinism is incompatible with $\diamond_{\mathrm{L}} \mathrm{IG}$. 
What Sehon says in favour of $\mathrm{P} 2$ is that determinism should not be incompatible with $\diamond_{\mathrm{L}} \mathrm{IG}$ because it is an empirical thesis. And an empirical thesis should not preclude a logical possibility.

Since the argument above is just a modus tollens, I will not question its validity. How can proponents of the Ramsey-Lewis account of laws reply to it?

In what follows, I will show how a Lewisian may reply to the argument above. It seems to me that she will contend premise 1 , since she will say that even if the Ramsey-Lewis account of laws is correct, determinism is compatible with an IG being logically possible. Now, remember that Sehon's main idea is not about an interventionist God in particular, but about the possibility of the laws being violated. So, the question here is the one whether the Humean conception of determinism is compatible with the logical possibility of the laws being violated. Thus, in order to show that P1 is false we need to show that the RamseyLewis view is consistent with the possibility of the laws being violated. The task then is to show that these two propositions are consistent:

$p:$ determinism is true
$q:$ it is possible to violate the laws

How can we do this? A simple strategy to show that $p$ and $q$ are consistent is to find a proposition $r$ whose conjunction with $p$ is both possible and entail $q$. If we can do this, then we will show that $p$ and $q$ are consistent. The proposition $r$ that will do the trick is the following:

$r$ : I am able to do something such that, if I did it, a law would be violated.

Now we need to show that $p$ is consistent with $r$. So I will employ the same strategy. I will find another proposition $s$ that is consistent with $p$ and show that the conjunction $p$ and $s$ entails $r$. The conjunction $p$ and $s$ is the thesis known as soft determinism, that is, the view that determinism is true and we are able to act otherwise. I will assume without any arguments that determinism is consistent with our ability to do otherwise (the reasons for this can be found in Beebee's paper 'Humean Compatibilism'). What I am going to do then is to put forward Lewis's defence of soft determinism (Lewis 1981: 114). I will assume that 
determinism is true and that sometimes we are able to act otherwise 4 . From this we will be able to infer $r$ and show that $p$ is consistent with $r$ (simply because if $p$ is the case and $p$ implies $r$, then the conjunction $p \& r$ is also the case, and so the conjunction is possible).

Let us assume then the truth of determinism, so that $\mathrm{P}_{0}$ and L logically imply, for instance, that I did not raise my hand; so they jointly contradict the proposition that I raised my hand. What if I had raised my hand? There are three options:

1. If I had raised my hand, contradictions would have been true.

2. If I had raised my hand, $\mathrm{P}_{0}$ would be false.

3. If I had raised my hand, $\mathrm{L}$ would be false.

Someone like Lewis will naturally reject options 1 and 2. Even if I had raised my hand, contradictions would not have been true. And even if I had raised my hand, the past would still be the same, so $\mathrm{P}_{0}$ would still be true ${ }^{5}$. Thus, if we want to say that determinism is true and sometimes we are able to act otherwise, the only option remaining is 3 . Thus, if determinism is true, then since determinism implies 3 , determinism is consistent with $r$, so the conjunction $p$ and $r$ is possible.

Now we need to show that the conjunction of $p \& r$ entails $q$. This is an easy task because $r$ itself entails $q$. But in order to see this we need to draw a distinction between two senses in which one can violate a law:

Weak sense: I am able to do something such that, if I did it, a law would be violated.

Strong sense: I am able to do something such that, if I did it, a law would be violated and this law would be of the same world where it is violated.

For example, in the weak sense, if I were to raise my hand, contrary to what determinism says, a law of nature would have been violated beforehand. To

\footnotetext{
${ }^{4}$ Notice that soft determinism is compatible with the Humean view of laws (see Beebee 2000: 579).

${ }^{5}$ Lewis (1979).
}

Manuscrito - Rev. Int. Fil., Campinas, v.39, n.1, pp. 73-95, jan.-mar. 2016. 
use Lewis's phrase, a 'divergence miracle' would have happened beforehand, that is, there would be a violation of the laws of nature, and this violation would not be caused by my action. Note that to say that there is a violation of the laws of nature in the weak sense is not to say that the violated laws are the laws of the same world where they are violated. The term 'miracle' is used to express a relation between different possible worlds. As Lewis says, 'a miracle at $w_{l}$, relative to $w_{0}$, is a violation at $w_{1}$ of the laws of $w_{0}$, which are at best the almost-laws of $w_{l}$ '(Lewis 1979: 469). Now, if by 'violating a law' we mean the weak sense, then I am able to violate a law iff I am able to do something such that, if I did it, a law would be violated. Thus, $r$ entails that I am able to violate a law, and since the proposition expressed by 'I am able to violate a law' entails $q, r$ entails $q$, and so $p \& r$ entails $q$. Hence, $p$ and $q$ are consistent.

But what if by 'violating the laws of nature' Sehon means the strong sense? The strong sense is the one in which the violated laws are the laws of the same world where they are violated. That is, a miracle in the strong sense happens, where a miracle in the strong sense at $w_{1}$, relative to $w_{0}$, is a violation at $w_{l}$ of the very same laws of $w_{1}$. This seems, in fact, what Sehon has in mind when he says that, if there is an IG, then it is possible that we have the same laws, the same past, and yet $\mathrm{P}$ is false. However, if by 'violating a law' Sehon means the strong sense, then someone like Lewis will deny that it is logically possible to violate a law in the strong sense. This is so because, as Lewis says, 'any genuine law is at least an absolutely unbroken regularity' (Lewis 1981: 114). Thus, it is a contradiction to say that something might be both a law and violated (or broken). Given the Ramsey-Lewis account of laws, it is clear why we cannot violate laws in the strong sense. Suppose it is a law that no object moves faster than light. If I were to throw an object that moves faster than light, then $\mathrm{L}$ would not be a law. Since for the Humean laws only summarize facts, if it is a fact that a certain stone moves faster than light, then the law that summarizes it must be different from the one that actually obtains.

To sum up, either Sehon means the strong sense or the weak sense in which it is possible to violate a law. If it is the strong sense, then the Humean will reject the premise that it is logically possible to violate a law in the strong sense. If it is the weak sense, then, as I showed, the Ramsey-Lewis conception of determinism is consistent with the laws being violated in the weak sense. In any case, it seems that the Humean has nothing to fear. 


\section{Determinism and the dispositional account of laws}

To recapitulate, if we assume Armstrong's account of laws, then we might read the box as metaphysical necessity and determinism would be compatible with an IG being logically possible. If, on the other hand, we endorse the Ramsey-Lewis account of laws, then it seems than an IG being logically possible is also compatible with determinism (even though the Humean has a different conception of what an IG is).

Lewis and Armstrong can be seen as figureheads for two rival camps concerning the study of laws of nature. One of the points they have in common, as I already indicated, is that they take (i) laws of nature to be metaphysically contingent rather than necessary. There is another, however, that I did not highlight when presenting their accounts of laws. Both take (ii) properties to be categorical rather than dispositional. In recent years a third view that explicitly rejects these two assumptions has emerged in the debates surrounding the nature of laws. This third view is known as dispositional essentialism, which was promoted, among others, by Alexander Bird. In this section I will briefly explore the implications that dispositionalism has for determinism, since I think it is the view that mainly motivates my understanding of determinism.

The dispositionalist view rejects the two assumptions above. First, according to the dispositionalist, laws of nature are metaphysically necessary, for reasons that we will see soon. Second, the dispositionalist takes at least some sparse properties (to use Lewis's terminology, that is, roughly those properties with which science is concerned) to be essentially dispositional. Intuitively, a disposition (or, to be more precise, overt disposition locutions) can be characterized as a tendency for something to manifest given a certain stimulus. For example, the disposition of a glass to break when struck can be characterized by the manifestation of breaking in response to the stimulus of being struck. It is usually suggested that there is a relation between a disposition and the truth of a counterfactual conditional connecting stimulus to manifestation. Take the glass's disposition to break for example. We are inclined to say that, if the glass were struck (that is, given this stimulus), then it would break (there would be the manifestation). This is the idea that motivates the conditional analysis of dispositions (CA). Where $D$ is the dispositional property, $S$ is the stimulus property and $M$ is the manifestation property, (CA) may be symbolized as follows: 


$$
\text { (CA) } D x \leftrightarrow \quad(S x \square \rightarrow M x)
$$

It is important to note that, according to dispositional essentialism, (CA) does not merely provide an analysis of the concept $D$; instead, it characterizes the nature of the property D. Thus, as Bird says, (CA) is metaphysically necessary:

$$
\left(\mathrm{CA}_{\square}\right) \square_{\mathrm{M}}(D x \leftrightarrow \quad(S x \square \rightarrow M x)) .
$$

As I mentioned earlier, the dispositionalist endorses the view that at least some sparse properties are essentially dispositional. To say that a property $P$ is essentially dispositional is to say that, necessarily, to instantiate $P$ is to possess a disposition to yield a manifestation in response to a stimulus:

$$
\left(\mathrm{DE}_{\mathrm{P}}\right) \square_{\mathrm{M}}(P \mathrm{X} \supset D x)
$$

At this stage we can explain how the dispositionalist can derive universal generalizations that are lawlike.

1. $\square_{\mathrm{M}}(P \mathrm{x} \supset(S x \square \rightarrow M x))$

2. $P \mathrm{x} \& S \mathrm{x}$

3. $M \mathrm{x}$

4. $(P \mathrm{x} \& S \mathrm{x}) \supset M \mathrm{x}$ from $\mathrm{CA}_{\square}$ and $\mathrm{DE}_{\mathrm{P}}$

assumption

from 1 and 2

from 2-3, I

Since one can generalize over the unbound variable $x$, we get from 4

5. $\forall \mathrm{x}((P x \& S x) \supset M x)$.

Hence, a universal generalization follows from $\left(\mathrm{CA}_{\square}\right)$ and $\left(\mathrm{DE}_{\mathrm{P}}\right)$. This is how the laws of nature are accounted for according to dispositionalism. 
Furthermore, since both $\left(\mathrm{CA}_{\square}\right)$ and $\left(\mathrm{DE}_{\mathrm{P}}\right)$ are metaphysically necessary, laws of nature are metaphysically necessary as well.

The problem, one may say, is that (CA) is false because of the existence of finkish dispositions and antidotes ${ }^{6}$. However, as Bird interestingly shows, rather than being a disadvantage for dispositionalism, this is actually one of its virtues, since the falsity of (CA) allows the dispositionalist to account for ceteris paribus laws. We can just replace the left-to-right implication of (CA) by

\section{$(\mathrm{CA} \supset$ *) $\mathrm{Dx} \supset(\mathrm{Sx} \&$ finks and antidotes to $D$ are absent $\square \rightarrow \mathrm{Mx})$.}

Now we deduce the following regularity:

$\forall \mathrm{x}$ (finks and antidotes to $D$ are absent $\supset((D x \& S x) \supset M x))$.

Since it admits exceptions, this is how the dispositionalist can account for ceteris paribus laws.

Given this brief presentation, we must now ask: how should the dispositionalist understand the notion of determinism?

${ }^{6}$ Let me present just one counterexample to (CA). Consider the left-to-right implication of (CA), for instance:

$(\mathrm{CA} \supset) D x \supset(S x \square \rightarrow M x)$.

A fragile glass has the disposition to break when struck. According to (CA $\supset$ ), it means that the glass would break if struck. But as Lewis tells us (Lewis 1997: 147), we may conceive a sorcerer that decides to protect a certain fragile glass. She does not to anything to change the glass's disposition; what she in fact does is to carefully watch the glass to ensure that whenever it is struck, she casts a spell that changes its structure in a way that its fragility is lost. So, if the glass were struck, it would not break, since the sorcerer would cast a spell that would make it no longer fragile. Thus, (CA $\supset$ ) is false, and this is so because Lewis's example is one where the disposition is finkish. That is, the object loses the disposition after the stimulus occurrence but before the occurrence of the manifestation in a way that the manifestation will not occur. 
Let us take again an intuitive grasp of what determinism is. Intuitively, determinism is the thesis according to which the past determines or fixes a unique future (van Inwagen 1983: 2). According to van Inwagen, it is the thesis that, given the past, there is exactly one possible future. But, again, what does it mean?

'Possible futures' is an ambiguous term. Depending on how we understand it, there are many 'possible futures'; as van Inwagen says, 'there are many ways in which the world could go on' (van Inwagen 1983: 3). For example, suppose that we understand 'possible futures' as conceivable futures. To use an example given by van Inwagen, 'There will be an eclipse this afternoon' is a sentence that expresses a proposition conceivable in the sense that one cannot detect any contradiction in the hypothesis that there will be an eclipse this afternoon. However, there is another sense in which this future is physically impossible. As van Inwagen says:

To say this [that this future is physically impossible] is not to say that it is contrary to the laws of nature - if we may allow ourselves this piece of terminology — that there should be an eclipse this afternoon, for the laws of nature do not by themselves dictate when particular events like eclipses shall occur. To say that a "possible future" containing an imminent eclipse is physically impossible is rather to say that given the past, the actual past, and the laws of nature, no eclipse will occur; that the past and the laws of nature together rule out any possibility of an eclipse this afternoon.

So, determinism is the thesis that there is at any instant exactly one physically possible future. All we need to do now is to see how the dispositionalist understands the notion of physical possibility. And the answer is straightforward, since for the dispositionalist there is only one genuine sort of modality, which is metaphysical modality. Other sorts of modality may be defined in terms of metaphysical modality. For example, as Bird writes, ' $p$ is nomologically necessary iff (the laws of nature $\rightarrow p$ ) is metaphysically necessary’ (Bird 2007: 48). Naturally, $p$ is nomologically possible iff $\sim \mathrm{p}$ is not nomologically necessary. Now we do the same trick to explain what a physically possible future is. Consider the notion of a physically necessary future: according to the dispositionalist, a future will be physically iff it is metaphysically necessary that the laws of nature and the past imply it. A future is physically possible iff its denial is not physically necessary. 
Now consider what determinism implies. If determinism is true, then $\square$ $\left(\left(\mathrm{P}_{0} \& \mathrm{~L}\right) \supset \mathrm{P}\right)$. Since metaphysical modality is the only genuine sort of modality, the box should be read as metaphysical necessity. So, if we assume the dispositionalist account of laws, determinism is compatible with an IG being logically possible.

However, someone could argue against this view as follows. Suppose that ' IG' is metaphysically possible. Therefore, using S4 or any stronger system, we could infer that determinism according to dispositionalism is false. In this case, the metaphysical conception of determinism is incompatible with the proposition that an interventionist God is metaphysically possible.

The reply above is not a problem for this paper, however. Sehon's main worry is that determinism, which is assumed as an empirical claim, precludes logical possibilities. This should not be so. Nevertheless, in this case, determinism does not preclude logical possibilities. Rather, it rules out metaphysical possibilities. This is not a problem if one assumes the dispositional account of laws, it seems. For the dispositionalist thinks that there are metaphysically necessary propositions that can be known only a posteriori. For instance, suppose the proposition expressed by 'water is $\mathrm{H}_{2} \mathrm{O}$ ' is one of them. 'Water is $\mathrm{H}_{2} \mathrm{O}$ ' is considered an empirical claim. Essentialism will tell us that, if water is $\mathrm{H}_{2} \mathrm{O}$, then it is not metaphysically possible that water is not $\mathrm{H}_{2} \mathrm{O}$. Empirical research is relevant to know whether some propositions are metaphysically possible.

Also, this is important because it shows how the dispositionalist can face what Sehon dubs the Epistemological Inscrutability Problem. Regarding determinism understood as involving logical necessity, the Epistemological Inscrutability Problem is this: how are we to know, or at least have a justified belief, that determinism is true? Determinism is supposed to be an empirical thesis. However, it is hard to see how (empirical) evidence could decide in favour of a logical necessity.

It does not seem that this conception of determinism must deal with this problem (if this is a problem at all) because dispositionalism takes determinism to involve metaphysical necessity and not logical necessity. Metaphysical necessities of the sort dispositionalists have in mind do involve (empirical) evidence. Thus Sehon's main worry does not apply here. Empirical research is as relevant to know whether determinism is true, in my understanding, as it is relevant to know whether water is essentially $\mathrm{H}_{2} \mathrm{O}$. If there is a problem here it is 
just the general problem of explaining the epistemology of metaphysical modality. And a general problem of this nature should not count against any conception of determinism.

\section{Conclusion}

This paper considered three accounts of laws. Armstrong's view might be in line with the conception of determinism as involving metaphysical necessity. The Ramsey-Lewis view, on the other hand, is not. However, I argued that this is not a particular problem for this view. Dispositional essentialism is the account of laws that mainly motivates to read the box of determinism as metaphysical necessity, and also gives reasons to reply to the Epistemological Inscrutability Problem. The overall conclusion is that Sehon's main worry does not seem to be a serious threat to the accounts considered in this paper.

\section{Acknowledgments}

Thanks to two anonymous referees for comments on this paper. Special thanks to Peter Vickers, Nancy Cartwright and Matthew Tugby for helpful and illuminating comments on a prior draft of this paper. I also gratefully acknowledge the CAPES Foundation for its financial support.

\section{References}

Armstrong, D. A World of States of Affairs. Cambridge: Cambridge University Press, 1997.

BeEbeE, H. The Nongoverning Conception of Laws of Nature, Philosophy and Phenomenological Research, 61: 571-594, 2000.

BIRD, A. Nature's Metaphysics: Laws and Properties. Oxford: Oxford University Press, 2007.

Carrolt, J. Laws of Nature. Cambridge: Cambridge University Press, 1994. 
FINE, Kit. "Guide to Ground" in Correia, F. and B. Schnieder (eds.), Metaphysical Grounding: Understanding the Structure of Reality, Cambridge: Cambridge University Press, 2012.

LEWIS, D. Counterfactuals, Cambridge: Harvard University Press, 1973.

"Counterfactual Dependence and Time's Arrow", Noûs, 13: 455-76, 1979.

“Are We Free to Break the Laws?", Theoria, 47: 113-21, 1981.

New Work for a Theory of Universals, Australasian Journal of Philosophy, 61: 343-377, 1983.

“Finkish Dispositions”, Philosophical Quarterly, 47: 143-158, 1997.

RAMSEY, F. Foundations, London: Routledge and Kegan Paul, 1978.

SEHON, S. A flawed conception of determinism in the Consequence Argument. Analysis 71 (1): 30-38, 2011.

SHALKOwSKI, S. A. Logic and Absolute Necessity. Journal of Philosophy CI, 2: 5582, 2004.

van Inwagen, P. An Essay on Free Will. Oxford: Clarendon Press, 1983. 
